\title{
Competition of spatial service hinterlands between high-speed rail and air transport in China: Present and future trends
}

WANG Jiaoe ${ }^{1}$, JIAO Jingjuan ${ }^{1,2}$, DU Chao ${ }^{1,2}, \mathrm{HU} \mathrm{Hao}^{3}$

1. Key Laboratory of Regional Sustainable Development Modeling, Institute of Geographic Sciences and Natural Resources Research, CAS, Beijing 100101, China;

2. University of Chinese Academy of Sciences, Beijing 100049, China;

3. Institute for Urban and Environmental Studies, Chinese Academy of Social Sciences, Beijing 100028, China

\begin{abstract}
The rapid development of high-speed rail (HSR) and air transport in China has encouraged research on the spatial effects and safety of these two modes of transport, and on the competition between them. We report here an investigation of the effects of competition between HSR and air transport in China from a geographical perspective. The spatial service hinterlands for HSR and air transport accessible within one and two hours by road transport were investigated using a method based on a geographical information system and the overlapping service hinterlands of HSR and air transport were established. A city with both HSR stations and airports, or that was accessible to HSR stations and airports within a certain travel time by road transport, was defined as the overlapping market. The spatial effects of competition between HSR and air transport at present and in the future were then studied with respect to the planned HSR network and airports. The results showed that both HSR and air transport tend to serve areas with high population densities and well-developed economies and in 2012 most of the population and GDP in China were accessible within two hours by road transport to an HSR station or airport. The different technical and economic characteristics of HSR and air transport determine the advantage markets. Spatially, the service hinterland of HSR mainly focuses on urban agglomerations and economic corridors in the eastern and central regions, whereas air transport has a competitive advantage in the more inaccessible western region of China. The overlapping market of HSR and air transport will become increasingly large in the future and cities with a population of over one million and cities within $30 \mathrm{~km}$ to both airports and HSR stations will become the major competitive markets. Considering the cost of construction and the number of passengers required for economic operation, as well as the competition with air transport, it is suggested that the construction of some HSR projects in the western region of China should be canceled or slowed down.
\end{abstract}

Keywords: high-speed rail; civil aviation; spatial analysis; service market; China

Received: 2014-09-15 Accepted: 2015-01-12

Foundation: National Natural Science Foundation of China, No. 41371143; No. 41171107; Programme of Bingwei Excellent Young Scientists of the Institute of Geographic Sciences and Natural Resources Research, CAS, No.2011RC201.

Author: Wang Jiaoe (1981-), Associate Researcher, specialized in transport geography and regional development studies. E-mail: wangje@igsnrr.ac.cn 


\section{Introduction}

As a result of the technical and economic characteristics of rail and air transportation, the reasonable transport distance and passenger markets of these two transport modes are very different. Conventional rail has advantages in terms of transport volume, low prices, and easier access; it is suitable for medium- and long-range trips and for passengers with low and middle incomes. In contrast, air transport has the characteristics of a low time cost and a high monetary price. However, the development of high-speed rail (HSR) has enabled rail transport to extend its transport distance and expand its market share. Many studies have focused on the competition between HSR and air transport (DGT, EC, 1998). Some European high-speed trains, such as the AVE in Spain, the Eurostar between France and the UK, and the Thalys between Paris, Brussels, and Amsterdam, demonstrate the ability of these services to attract substantial shares of the intercity travel market from air travel (Capon et al., 2003).

Total journey time (including access time, waiting time and travel time), frequency and fares are common variables for researching the competition between HSR and air transport (Dobruszkes, 2011). With six railway speed-up campaigns and the large-scale construction of passenger dedicated lines (PDL), China's rail system has entered into a 'high-speed' period and air transport has been greatly affected. For example, the development of HSR intensifies 'time-space convergence' and the 'city effect' (Wang and Ding, 2011) and also increasingly blurs the cut-off between the rail and air passenger markets; HSR then begins to control part of the original aviation markets. Although the impacts of HSR on civil aviation are relevant to the route distance (travel time), market, and passengers, some workers have suggested that more than $60 \%$ of the domestic civil aviation market will be affected at different levels after the formation of China's 'four-vertical and four-horizontal' PDLs (Chen, 2010). However, if transport hubs that combine airports with HSR stations are integrated, there is the potential for rail and air services to complement each other rather than to compete. Passengers could then purchase tickets for both the HSR and air transport at the same time, travel to the airport by HSR, and then take a longer distance flight.

HSR is defined in the European Directive on Interoperability as a rail line on which trains run at a maximum speed of at least $250 \mathrm{~km} / \mathrm{h}$. With the continuous construction of HSR, competition and cooperation between HSR and civil aviation transportation have attracted the attention of both Chinese and other researchers. At present, studies about the impacts of HSR on air transport have concentrated on the following aspects: the analysis of the impacts of HSR on the civil aviation market from the perspective of qualitative analysis (Zhang and $\mathrm{Hu}, 2010$; Peng and Hu, 2009; Wang, 2010; Guo, 2010; Huang, 2010); the influence of HSR on the passenger flow of air transport (Liu et al., 2007; Ding, 2009); the measures taken by air transport in response to competition from HSR; and the changes in passenger flow between cities using either HSR or air transport by analyzing historical data (Dobruszkes, 2011). Another method of analysis is the study of the relationship between HSR and air transport over different distances, which has shown that HSR and civil aviation are competitive over different travel distances (Park and Ha, 2006; Adler et al., 2010). The third method is to quantitatively analyze and simulate the costs and benefits of HSR and air transport by using a cost-benefit model that divides the total travel time into the arrival time, waiting time, and travel time (Bel, 1997; González-Savignat, 2004; Mao, 2010; Román et al., 2007, 
2010).

Although some researchers have already carried out work on the competition between HSR and air transport, and have paid close attention to the relationship between the evolution of urban spatial structure and urban accessibility (Wang and Lin, 2011; Meng and Lu, 2012), studies of the spatial competition of the service market between HSR and air transport are rare. At present, the service market of the HSR network in China is concentrated in the central and eastern regions, whereas that of air transport is concentrated in the enclosed region surrounded by Beijing, Shanghai, Guangzhou, and Chengdu. Therefore there are overlaps in the service market of HSR and air transport, with the exception of transportation distance. Based on the spatial analysis tools in ArcGIS, we evaluated and simulated the distribution of HSR and air transport, analyzed the service market of HSR stations and airports, explored the overlapping areas, and examined the advantage areas of different transport modes with the aim of providing references for related research.

\section{Data processing and methodology}

\subsection{Data processing}

The HSR network in China is divided by the Ministry of Railways (MOR) into four parts: (1) upgraded pre-existing rail lines with speeds $>200 \mathrm{~km} / \mathrm{h}$; (2) PDLs with speeds $>250 \mathrm{~km} / \mathrm{h}$; (3) newly built conventional rail lines with speeds of $200-250 \mathrm{~km} / \mathrm{h}$ for both passengers and freight; and (4) intercity HSR lines with speeds $>250 \mathrm{~km} / \mathrm{h}$. However, as a result of the Wenzhou-Yongjia HSR line accident in 2011, the average operating speed of the high-speed trains running on some of the upgraded conventional rail lines has been reduced to $160 \mathrm{~km} / \mathrm{h}$ (Jiao et al., 2014). Therefore, in this work, the HSR network was defined as newly built rail lines with average speeds $>250 \mathrm{~km} / \mathrm{h}$ and upgraded rail lines with average speeds $>160 \mathrm{~km} / \mathrm{h}$. In 2012, the HSR lines included those rail lines with trains with $\mathrm{G}, \mathrm{C}$, and D prefixes (Figure 1). The HSR lines currently being planned for 2020 in the mainland of China consist of $12,000 \mathrm{~km}$ of four-vertical and four-horizontal PDLs, $4000 \mathrm{~km}$ of intercity HSR lines, and 25,000 km of upgraded HSR lines (MOR, 2008), excluding Hong Kong, Macao and Taiwan (Figure 1). By the end of 2012, China operated 183 civil airports, although three of these were suspended (Baoanying, Qiemo, and Ankang), and there will be 245 civil aviation airports by 2015 in the mainland of China (excluding Hong Kong, Macao, and Taiwan) (CAAC, 2011). The locations of the HSR stations and the airports in operation were obtained from their latitude and longitude, while the planned HSR network and airports were digitized based on the planning map (Figure 1). Other relevant data (e.g. the data of the ground transport network in 2012) was mainly derived from the China Transportation Yearbook 2013, the Institute of Mainland System Theme Database and the National Mapping Agency National Geomatics Center 1:4,000,000 Map Database.

This work took 2011 as the basic year for the socio-economic and administrative units. Geographical information system (GIS) data for the administrative units was digitized according to 2012 People's Republic of Administrative Divisions Booklet, which helps to match and calibrate four municipalities, 333 prefecture-level administrative units (including 283 prefecture-level cities, 17 regions, 30 autonomous prefectures, and three leagues) and 2354 county-level administrative units based on data from China's Sixth National Census. 
All the data for the population and the GDP were sourced from the China City Statistical Yearbook 2012, China's Regional Economic Statistical Yearbook 2012, and China Population and Employment Statistics Yearbook 2012 (NBSC, 2012a, 2012b, 2012c). The cities were classified into five types based on the population of the municipal districts. The five types are: three megacities (Beijing, Shanghai, and Chongqing with a population $>10$ million); 16 very large cities (population 3-10 million), 108 large cities (population 1-3 million), 118 medium-sized cities (population 0.5-1 million), and 92 small cities (population $<0.5$ million).

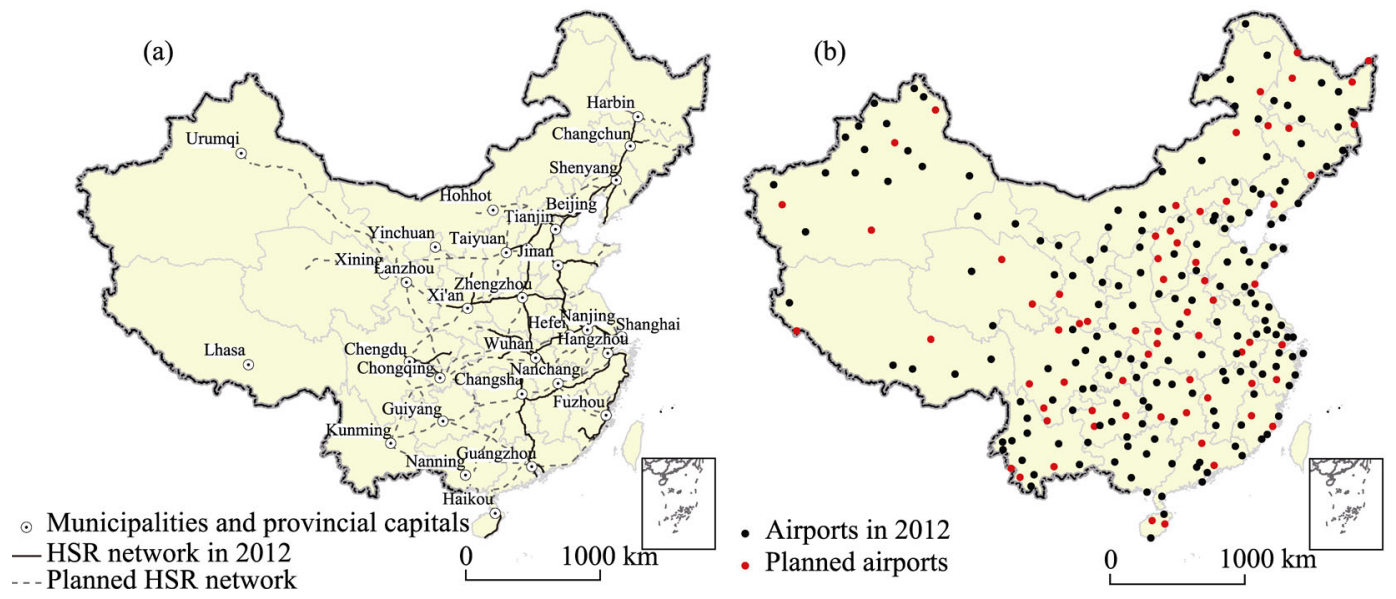

Figure 1 Spatial distribution of the present and planned HSR network and airports in China

\subsection{Methodology}

Accessibility is traditionally defined as the potential of opportunities for interaction (Hansen, 1959) and is widely used in the field of transport networks, transport planning, and land use studies. There are many indicators of accessibility, including measurements of spatial separation, contours, gravity, competition, time-space, utilities, and networks (Curtis and Scheurer, 2010). The cost of travel forms the basis of these indicators, including travel time, travel distance, and travel expenses. HSR lines are characterized by their high speed, which largely reduces the travel time between two cities and travel time is therefore used here as the basic unit to measure accessibility. To calculate the accessibility of the HSR stations and airports, the road network is selected as the basic map. A $1 \times 1 \mathrm{~km}$ raster cell was used as the basic calculation unit and the value of each cell was defined as the shortest travel time by the fastest transport mode to pass through it. The speed of travel by the road network was computed separately for expressways $(100 \mathrm{~km} / \mathrm{h})$, national roads $(80 \mathrm{~km} / \mathrm{h})$, and provincial roads $(60 \mathrm{~km} / \mathrm{h})$ in accordance with Chinese road engineering technical standards. The average travel speed was set as $30 \mathrm{~km} / \mathrm{h}$ in urban areas. The time parameter for raster cells without any transport modes was set to be equivalent to the speed of walking $(15 \mathrm{~km} / \mathrm{h})$. All the calculations were completed using the spatial analysis tools in ArcGIS.

The 333 prefecture-level administrative units and the 2354 county-level administrative units were used as the basic unit to evaluate the service hinterlands of the HSR stations and airports. If the administrative center of the basic unit was located in the rational service range of the HSR stations or airports (one or two hours), then the unit was defined as the 
service hinterland of the HSR stations or airports. If the city or county was served by several HSR stations or airports, it was assigned to the service hinterland of the nearest facility according to the minimum time principle. It was assumed that the HSR stations and airports were completely connected with the road network (Wang et al., 2006) and that the transport modes chosen were determined by the shortest travel time. The service hinterlands of the HSR stations and airports were calculated separately. The areas of the service hinterlands overlapped by the HSR network and the airports were analyzed from two perspectives: (1) cities with both HSR stations and airports; and (2) cities located in the service hinterland within one or two hours of both HSR stations and airports. On this basis, the cooperation and competition of the HSR network and aviation were analyzed.

\section{Service hinterland}

The impacts of the HSR network are influenced by the location of the HSR station and its accessibility to the hinterland by road transport; cities mainly benefit from the construction of HSR stations by a growth in their economy and passenger traffic (Adler et al., 2010). The economic growth of cities is closely related to both air transportation and the HSR, which attract both people and foreign investment. In China, the construction or planning of the HSR stations and airports is chiefly determined by the population size and the GDP of the cities. Based on both prefecture-level and county-level administrative units, we analyzed the service hinterlands of the HSR stations and airports by examining the areas where HSR stations and airports were located, or could be accessed within one or two hours by road transport, and then summarized the population and GDP in the service hinterlands.

\subsection{HSR stations}

The service hinterland of the HSR network is mainly concentrated along the HSR lines, such as Beijing-Guangzhou, Beijing-Harbin, Beijing-Shanghai, and Shanghai-HangzhouFuzhou (Figure 2). Most of the service hinterland is located in the eastern region, especially along the economic corridors and the areas with good natural conditions, a dense population, high economic value, and concentrated traffic flows. The service hinterland accessible to the HSR stations within one hour by road transport accounts for $33.495 \%$ of the area of the eastern region, $10.52 \%$ of the central region, and just $1.35 \%$ of the western region. In terms of the two hour service hinterland, the percentages increase to $66.94,26.7$, and $4.19 \%$, respectively. The service hinterland within one hour of the HSR network in the eastern region is basically joined in space and that within two hours has formed a continuous area. The service hinterland of the HSR network may be influenced by the location of the HSR stations and the density and grade of the road network. At the provincial and prefecture levels, the provinces and cities with $>50 \%$ area coverage within one hour include Shanghai $(82.08 \%)$, Zhejiang Province (54.53\%), and Beijing (53.9\%). Over 30\% of the area of Hainan Province, Henan Province, Hunan Province, Shandong Province, and Liaoning Province reach a HSR station within one hour by road transport, whereas the areas of Guangxi, Guizhou, Ningxia, Qinghai, Tibet, Xinjiang, and Yunnan cannot access an HSR station within one hour. With regard to accessibility within two hours, the service hinterland of the HSR network covers over $80 \%$ of the area of Beijing, Tianjin, Shanghai and Shandong, Henan, and Zhejiang and nearly two-thirds of the area of Anhui, Hubei, Liaoning, and Jiangsu. 

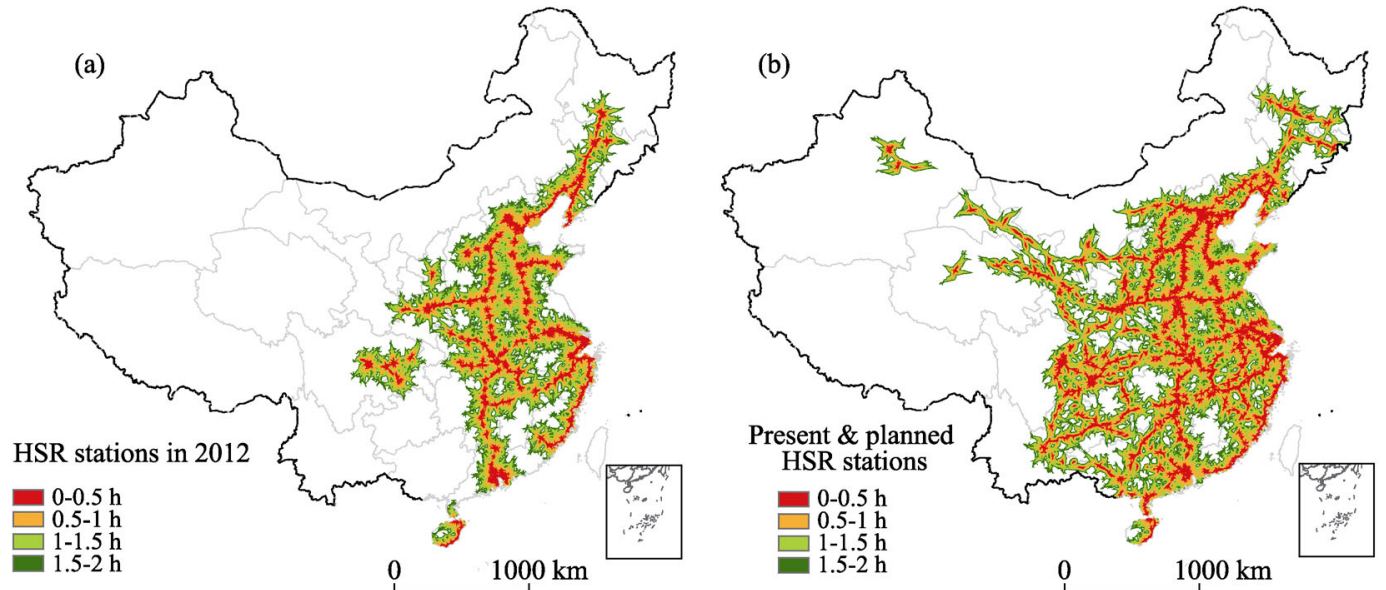

Figure 2 Areas accessible to the HSR stations within two hours by road transport (present and future)

With the future construction of the HSR network, the service hinterland will gradually expand to the western region of China. The one hour service hinterland of the HSR will become an important corridor connecting northeast China, north China, central China, south China, and even southwest China (Figure 3). In the planned HSR network, the one and two hour service hinterland of the HSR will expand to 1.62 million and 3.26 million $\mathrm{km}^{2}$, respectively, from 0.85 million and 1.83 million $\mathrm{km}^{2}$ in 2012 . Spatially, the coverage rate of the one hour service hinterland with the planned HSR network will increase to $52.04 \%$ (the eastern region), $19.77 \%$ (the central region), and $9.12 \%$ (the western region), which is much higher than that in 2012. Over 90\% of the area of Tianjin, Beijing, Chongqing, Anhui, Henan, Fujian, Shandong, Zhejiang, Hubei, and Jiangsu will be covered by the two hour service hinterland of the planned HSR network. The provinces located in the western region will have a large increase in the coverage rate after the opening of the planned HSR network, whereas none of the area of Tibet will be able to reach an HSR station within two hours.

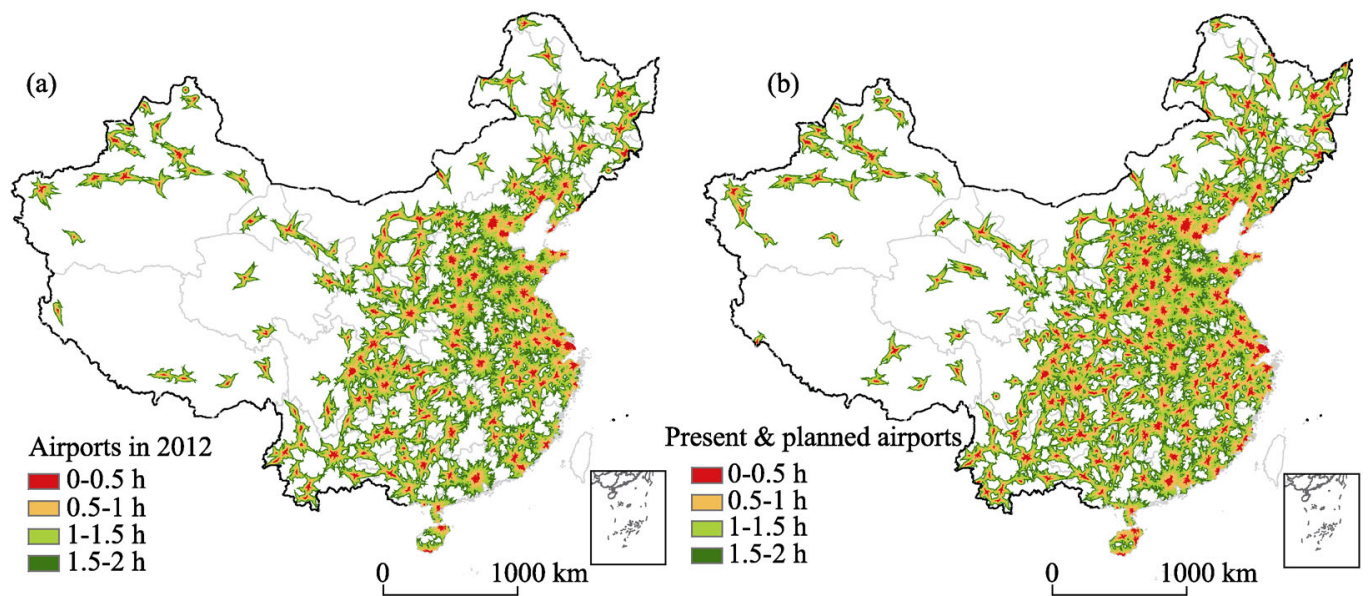

Figure 3 Areas accessible to airports within two hours by road transport

\subsection{Airports}

Air transport has more advantages than the HSR network in western China, with its large 
and sparsely populated area and harsh terrains, which cannot attract sufficiently high passenger flows for the operation of high-speed trains. The one hour service hinterland of the airports is distributed discretely in the western region (Figure 3), whereas in the eastern and central regions it is spatially continuous. The coverage rates of the service hinterland of the airports show a decreasing trend from the eastern region via the central region to the western region, in line with the spatial distribution of the population and the GDP in China. Specifically, the coverage rate of the one hour service hinterland decreases from $22.81 \%$ in the eastern region to $8.77 \%$ in the central region, and to $5.62 \%$ in the western region; the coverage rate of the two hour service hinterland of the eastern region is 1.87 times and 3.13 times that in the central and western regions, respectively. The central and eastern regions have a relatively higher coverage rate of airports in terms of the one hour service hinterland than for the HSR network; the coverage rate of the two hour service hinterland of the airports in all three regions are much higher than that of the HSR network. Specifically, the coverage rate of the two hour service hinterland of airports is 1.06 times (the eastern region), 1.42 times (the central region), and 5.41 times (the western region) that of the HSR network.

At the provincial and prefecture level, about half of the areas of Shanghai, Tianjin, Beijing, and Jiangsu were covered by the one hour service hinterland of airports in 2012 and over $80 \%$ of the areas of Tianjin, Beijing, Jiangsu, Shandong, Zhejiang, Shanghai, and Ningxia could reach the service of airports within two hours in 2012. Compared with the HSR network in 2012, airports did not have any advantages in Fujian, Hainan, Hebei, Henan, Hubei, Liaoning, Shandong, and Zhejiang in terms of the two hour service hinterland. In other words, most provinces and cities were much more accessible within two hours by road transport to the nearest airports than to the HSR stations in 2012. With the construction of the planned airports, the service hinterland of the airports in all the provinces (except for Shanghai, Tianjin, and Ningxia) will increase. However, most cities in the hinterland are located in the eastern and central regions, which is different from the situation with regard to the HSR network. Specifically, the increase of over $15 \%$ in the coverage rate within the two hour service hinterland with the planned airports is 22.24\% (Jilin Province), $19.05 \%$ (Shanxi Province), 18.57\% (Henan Province), and 16.7\% (Hebei Province). However, only a few provinces, including Jilin, Hainan, Heilongjiang, Yunnan, Sichuan, Xinjiang, Inner Mongolia, Tibet, Jiangsu, and Ningxia, will be much more accessible within two hours to the nearest airports than to the HSR stations as the planned HSR network and airports open. Spatially, the one hour service hinterland of the airports has formed continuous regions in the south of Jiangsu Province, in the central Anhui Province and Guizhou Province, and along the Hangzhou-Shangrao, Zhengzhou-Luoyang-Nanyang-Shiyan, and Shenyang-JinzhouDalian corridors (Figure 3). The Bohai Rim region (especially the Beijing-Tianjin-Hebei region) and the Yangtze River Delta enjoy higher accessibility to airports by road transport than the Pearl River Delta.

\subsection{Comparison between HSR stations and airports}

The civil aviation service has a number of competitive advantages over HSR in the various study units in terms of the population and GDP served by the present airports within a certain travel distance (Table 1). Specifically, 192 cities $(56.97 \%$ of the total) were located within the one hour service hinterland of airports in 2012, which is 1.33 times higher than that for the HSR stations. The accessible population and GDP within a one hour reach of the 
HSR stations were 776.73 million people (58.94\% of the total) and 3734.7 billion yuan (70.75\% of the total). The accessible population and GDP within a one hour reach of the airports were 854.56 million people $(64.84 \%)$ and 38917.95 billion yuan $(73.72 \%)$. Although the service hinterlands of the airports and the HSR stations were distributed differently spatially, they also had some overlapping areas in the eastern region, with its high population densities and well-developed economies. The two hour service hinterland of the airports covered 303 cities, 1248.04 million people and 51143.7 billion yuan, more than $90 \%$ of the national level and a much larger percentage than the HSR network.

In terms of the county-level administrative units, the one hour service hinterland of the HSR covered 695 units $(29.52 \%)$, which was a little higher than that of the airports (671 units). This is probably caused by the high density of HSR stations, counties and urban districts in the eastern region. A total of $47.23 \%$ of the population and $62.6 \%$ of the GDP were located in the one hour service hinterland of the HSR network; $51.32 \%$ of the counties and urban districts, $69.22 \%$ of the population, and $78.84 \%$ of the GDP were located in the two hour service hinterland of the HSR network. However, the percentages of population $(85.46 \%)$ and GDP (91.68\%) accessible within two hours of the airports were much higher than that of the county-level units $(70.9 \%)$.

Table 1 Socio-economic attributes of areas within one and two hours of the HSR stations and airports, 2012

\begin{tabular}{|c|c|c|c|c|c|c|c|c|c|}
\hline \multirow[b]{2}{*}{ Unit } & \multirow[b]{2}{*}{ Time } & \multicolumn{4}{|c|}{ HSR station } & \multicolumn{4}{|c|}{ Airport } \\
\hline & & $\begin{array}{c}\text { Number } \\
(\%)\end{array}$ & $\begin{array}{c}\text { Area } \\
\left(10^{4} \mathrm{~km}^{2}\right) \\
(\%)\end{array}$ & $\begin{array}{c}\text { Population } \\
\left(10^{4} \text { people }\right) \\
(\%)\end{array}$ & $\begin{array}{c}\text { GDP } \\
\left(10^{8} \text { yuan }\right) \\
(\%)\end{array}$ & $\begin{array}{c}\text { Number } \\
(\%)\end{array}$ & $\begin{array}{c}\text { Area } \\
\left(10^{4} \mathrm{~km}^{2}\right) \\
(\%)\end{array}$ & $\begin{array}{c}\text { Population } \\
\left(10^{4} \text { people) }\right. \\
(\%)\end{array}$ & $\begin{array}{c}\text { GDP } \\
\left(10^{8} \text { yuan }\right)\end{array}$ \\
\hline \multirow{2}{*}{$\begin{array}{c}\text { Prefecture- } \\
\text { level city }\end{array}$} & $\begin{array}{l}\text { One } \\
\text { hour }\end{array}$ & $\begin{array}{c}144 \\
(42.72)\end{array}$ & $\begin{array}{l}84.99 \\
(8.99)\end{array}$ & $\begin{array}{l}77,673 \\
(58.94)\end{array}$ & $\begin{array}{c}373,471 \\
(70.75)\end{array}$ & $\begin{array}{c}192 \\
(56.97)\end{array}$ & $\begin{array}{c}94.62 \\
(10.01)\end{array}$ & $\begin{array}{l}85,456 \\
(64.84)\end{array}$ & $\begin{array}{c}389,179.5 \\
(73.72)\end{array}$ \\
\hline & $\begin{array}{l}\text { Two } \\
\text { hours }\end{array}$ & $\begin{array}{c}196 \\
(58.16)\end{array}$ & $\begin{array}{l}183.06 \\
(19.36)\end{array}$ & $\begin{array}{l}97,428 \\
(73.92)\end{array}$ & $\begin{array}{r}431,927 \\
(81.82)\end{array}$ & $\begin{array}{c}303 \\
(89.91)\end{array}$ & $\begin{array}{l}319.04 \\
(33.75)\end{array}$ & $\begin{array}{c}124,804 \\
(94.7)\end{array}$ & $\begin{array}{c}511,437 \\
(96.89)\end{array}$ \\
\hline \multirow{2}{*}{$\begin{array}{l}\text { County } \\
\text { level unit }\end{array}$} & $\begin{array}{l}\text { One } \\
\text { hour }\end{array}$ & $\begin{array}{c}695 \\
(29.52)\end{array}$ & \multirow{2}{*}{-} & $\begin{array}{l}63,047 \\
(47.23)\end{array}$ & $\begin{array}{c}274,769 \\
(62.6)\end{array}$ & $\begin{array}{c}671 \\
(28.5)\end{array}$ & \multirow{2}{*}{-} & $\begin{array}{l}61,096 \\
(45.77)\end{array}$ & $\begin{array}{c}270,057 \\
(61.53)\end{array}$ \\
\hline & $\begin{array}{l}\text { Two } \\
\text { hours }\end{array}$ & $\begin{array}{c}1208 \\
(51.32)\end{array}$ & & $\begin{array}{l}92,393 \\
(69.22)\end{array}$ & $\begin{array}{c}346,043 \\
(78.84)\end{array}$ & $\begin{array}{c}1669 \\
(70.9)\end{array}$ & & $\begin{array}{c}114,079 \\
(85.46)\end{array}$ & $\begin{array}{c}402,405 \\
(91.68)\end{array}$ \\
\hline
\end{tabular}

Note: The areas are those areas accessible by the HSR stations or airports by road in either one or two hours.

With the planned HSR network, the service hinterland of HSR will become congruent with that of air transport and the amount of overlapping areas will show a large increase (Table 2). From the perspective of the prefecture-level cities, the accessible population and GDP within one hour of an airport will reach 997.7 million people (75.7\% of the total) and 42821.5 billion yuan $(81.08 \%$ of the total). The percentages in the two hour service hinterland of the HSR network for prefecture-level cities will increase from $74.93 \%$ in 2012 to $93.77 \%$ by population and from 82.39 to $95.84 \%$ by GDP. A total of 1099.3 million people and 46747 billion yuan are served by the one hour service hinterland of HSR. In other words, the service hinterland of the HSR network exceeds that of air transport if we take into account the planned HSR network and airports. The increased ratio of the accessible population and the GDP to airports is much lower than that for the HSR network. Although the areas of the service hinterlands for air transport and the HSR network show some differences, the scale of accessible population and GDP are similar. The two hour service hinterlands of planned airports and the HSR network covers all the cities with a population over one mil- 
lion and the developed areas, which will become the most important markets for both transport modes. Spatially, the regions located at the east of the Heihe-Tengchong line, in Xi'an, in the Chengdu-Chongqing economic zone, in Lanzhou, and in areas on the northern slopes of Tianshan Mountains are the major overlapping service areas of air transport and the HSR network.

Table 2 Socio-economic attributes of areas within two hours of the present and planned HSR stations and airports

\begin{tabular}{|c|c|c|c|c|c|c|c|c|c|}
\hline \multirow[b]{2}{*}{ Unit } & \multirow[b]{2}{*}{$\begin{array}{l}\text { Time by } \\
\text { road } \\
\text { transport }\end{array}$} & \multicolumn{4}{|c|}{ HSR station } & \multicolumn{4}{|c|}{ Airport } \\
\hline & & $\begin{array}{c}\text { Number } \\
(\%)\end{array}$ & $\begin{array}{c}\text { Area } \\
\left(10^{4} \mathrm{~km}^{2}\right) \\
(\%)\end{array}$ & $\begin{array}{l}\text { Population } \\
10^{4} \text { people } \\
\text { (\%) }\end{array}$ & $\begin{array}{c}\text { GDP } \\
10^{8} \text { yuan } \\
(\%)\end{array}$ & $\begin{array}{c}\text { Number } \\
(\%)\end{array}$ & $\begin{array}{c}\text { Area } \\
\left(10^{4} \mathrm{~km}^{2}\right) \\
(\%)\end{array}$ & $\begin{array}{l}\text { Population } \\
10^{4} \text { people } \\
\quad(\%)\end{array}$ & $\begin{array}{c}\text { GDP } \\
10^{8} \text { yuan } \\
(\%)\end{array}$ \\
\hline \multirow{2}{*}{$\begin{array}{l}\text { Prefecture- } \\
\text { level city }\end{array}$} & $\begin{array}{l}\text { One } \\
\text { hour }\end{array}$ & $\begin{array}{c}237 \\
(70.33)\end{array}$ & $\begin{array}{c}161.6 \\
(16.93)\end{array}$ & $\begin{array}{c}109,931 \\
(83.41)\end{array}$ & $\begin{array}{c}467,470 \\
(88.51)\end{array}$ & $\begin{array}{c}235 \\
(69.73)\end{array}$ & $\begin{array}{l}104.07 \\
(10.9)\end{array}$ & $\begin{array}{c}99,770 \\
(75.7)\end{array}$ & $\begin{array}{c}428,215 \\
(81.08)\end{array}$ \\
\hline & $\begin{array}{l}\text { Two } \\
\text { hours }\end{array}$ & $\begin{array}{c}280 \\
(83.09)\end{array}$ & $\begin{array}{l}325.73 \\
(34.12)\end{array}$ & $\begin{array}{c}123,582 \\
(93.77)\end{array}$ & $\begin{array}{c}506,202 \\
(95.84)\end{array}$ & $\begin{array}{c}324 \\
(235)\end{array}$ & $\begin{array}{l}368.22 \\
(38.57)\end{array}$ & $\begin{array}{c}130,613 \\
(99.1)\end{array}$ & $\begin{array}{c}523,878 \\
(99.19)\end{array}$ \\
\hline \multirow{2}{*}{$\begin{array}{l}\text { County } \\
\text { level unit }\end{array}$} & $\begin{array}{l}\text { One } \\
\text { hour }\end{array}$ & $\begin{array}{c}976 \\
(41.48)\end{array}$ & \multirow{2}{*}{-} & $\begin{array}{l}79,642 \\
(59.76)\end{array}$ & $\begin{array}{c}325,282 \\
(74.95)\end{array}$ & $\begin{array}{l}706 \\
(30)\end{array}$ & \multirow{2}{*}{-} & $\begin{array}{l}58,709 \\
(44.05)\end{array}$ & $\begin{array}{c}251,558 \\
(57.97)\end{array}$ \\
\hline & $\begin{array}{l}\text { Two } \\
\text { hours }\end{array}$ & $\begin{array}{c}1739 \\
(73.91)\end{array}$ & & $\begin{array}{l}117,916 \\
(88.47)\end{array}$ & $\begin{array}{c}404,675 \\
(93.25)\end{array}$ & $\begin{array}{c}1784 \\
(75.82)\end{array}$ & & $\begin{array}{l}116,842 \\
(87.67)\end{array}$ & $\begin{array}{c}406,892 \\
(93.76)\end{array}$ \\
\hline
\end{tabular}

\section{Competition from a geographical perspective}

Both air transport and HSR are much more expensive modes of transport than conventional rail. However, air transport and HSR, which are characterized by high speeds, have a large market in cities with high population densities and well-developed economies. This section analyzes the competition between HSR and air transport from the perspective of the overlapping market, major competitive markets, and the distance to the city center.

\subsection{Overlapping market}

It is important to measure the overlapping market of HSR and air transport to analyze the competition between them. Two measures were adopted in the following analysis.

The first method summarized the characteristics of the cities where both HSR stations and airports were located in the administrative areas. In 2012, 180 airports and 304 HSR stations were located in 167 cities and 111 cities, respectively. Fifty cities had both HSR stations and airports (Figure 4), of which 39 were located in the eastern region or provincial capitals. Most of these cities were municipalities, provincial capitals, or located around the Beijing-Tianjin-Hebei region, the Yangtze River Delta, the Pearl River Delta, the ChengduChongqing economic zone, the Harbin-Changchun-Shenyang HSR corridor, or the Hangzhou-Ningbo-Xiamen-Fuzhou corridor. With the development of the planned HSR network and airports, the number of cities with both HSR stations and airports will increase to 131 . Of these cities, around half will be located in the western region and only 32.8 and $19.8 \%$ in the central and eastern regions, respectively. Specifically, increasing numbers of cities in the western region plan to construct HSR stations in their administrative areas. In other words, the air travel market in the western region will be influenced by the construction of the HSR network. The spatially continuous areas of Beijing, Tianjin, and the northern parts of Hebei and Shanxi provinces face competition between HSR and air transport.

The other method used to analyze the competition between air transport and HSR exam- 
ined the overlapping market of air transport and HSR accessible within one or two hours by road transport (Figure 5). In 2012, 52 airports were located in the one hour service hinterland of HSR and 70 airports were located in the two hour service hinterland. A total of 81 cities were located in the one hour service hinterlands of both HSR and airports, and 188 cities within the two hour service hinterlands. All these cities were concentrated along the trunk HSR lines, in particular at the intersection of the HSR lines or around cities with high population densities and well-developed economies, such as Beijing, Tianjin, Chongqing, Guang-

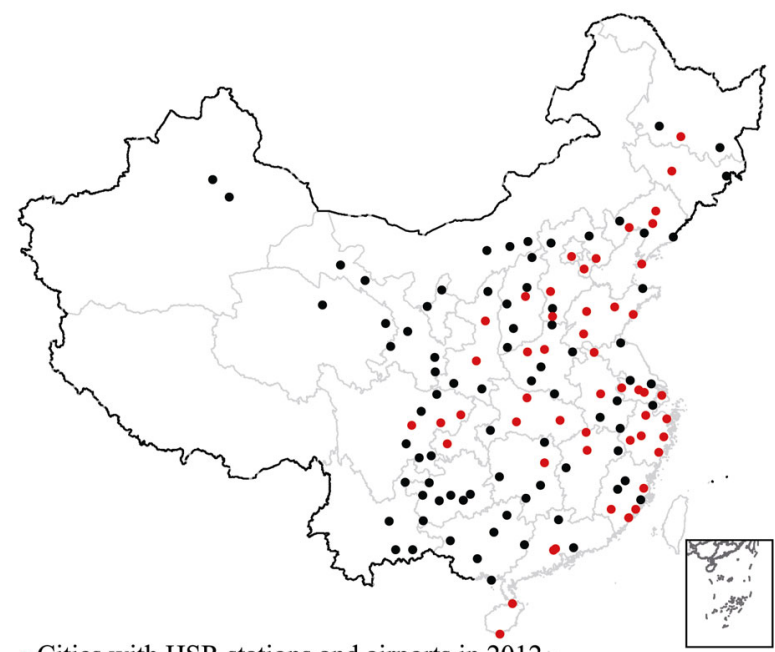

- Cities with HSR stations and airports in 2012

- Cities with planned HSR stations and airports $1000 \mathrm{~km}$

Figure 4 Distribution of overlapping market areas by HSR stations and airports zhou, and Shanghai. In all these cities, the distance (accessible distance) between the HSR stations and the airports is fairly short, which presents a challenge with respect to competition between air transport and HSR. As the planned development of air transport and HSR proceeds, the number of airports and HSR stations will show a large increase. The number of airports located in the one and two hour service hinterland of the HSR network will increase to 127 and 163, respectively. In other words, the overlapping market between air transport and HSR will become much larger in the future, so it is important for both air transport and HSR to recognize their own advantages to passengers and improve the efficiency and quality of their service.
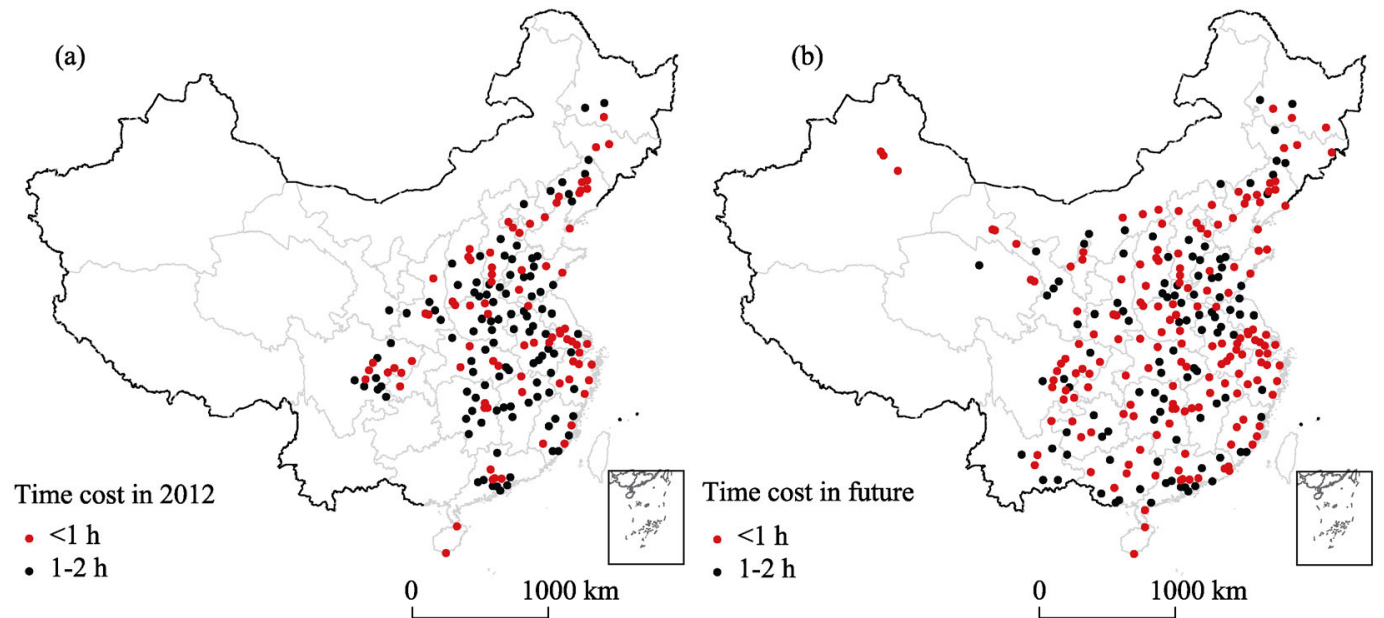

Figure 5 Distribution of cities within the service hinterlands of HSR and air transport

Cities with both HSR stations and airports are the most competitive market between HSR and air transport, whereas cities located within the one or two hour catchment areas form a 
sub-competitive market. With the development of the planned HSR stations and airports, the competitive market will greatly expand, especially in terms of the accessible population and GDP within two hours (Table 3). In 2012, there were just 50 cities with the HSR stations and airports and the GDP and population of these cities accounted for $43.6 \%$ and $29.5 \%$, respectively; this will increase to $60.1 \%$ and $51.6 \%$, respectively, with the planned expansion of the HSR stations and airports. In addition, over half of the population and the GDP are in the most competitive market. Around $24 \%$ of cities, $54.3 \%$ of GDP, and $39.4 \%$ of the population could access the services of HSR and air transport within one hour in 2012; these percentages will increase to $34.4 \%, 72.2 \%$, and $62.8 \%$, respectively, with the planned increases in the transport network. More than $70 \%$ of the population and the GDP could access the nearest airport or the HSR stations within two hours by road transport. All these areas are the sub-competitive markets of HSR and air transport. Some regions are only located in the two hour service hinterland of the HSR stations or airports and these are called the advantages regions of the HSR stations or airports. In these regions, people tend to choose one transport mode of either air transport or HSR. However, some places are still located beyond the two hour service hinterlands of both HSR stations and airports and people in these regions find it difficult to enjoy the benefits of high-speed transport.

Table 3 Socio-economic attributes of overlapping areas covered by the present and future HSR stations and airports

\begin{tabular}{|c|c|c|c|c|c|c|c|c|c|}
\hline \multirow[b]{2}{*}{ Time } & \multirow{2}{*}{$\begin{array}{l}\text { Socio-economic } \\
\text { attribute }\end{array}$} & \multicolumn{4}{|c|}{ Present } & \multicolumn{4}{|c|}{ Future } \\
\hline & & Both & $\begin{array}{l}\text { HSR station } \\
\text { only }\end{array}$ & $\begin{array}{l}\text { Airport } \\
\text { only }\end{array}$ & Neither & Both & $\begin{array}{l}\text { HSR station } \\
\text { only }\end{array}$ & $\begin{array}{c}\text { Airport } \\
\text { only }\end{array}$ & Neither \\
\hline \multirow{3}{*}{$\begin{array}{l}\text { Prefecture-level } \\
\text { administrative } \\
\text { coverage }\end{array}$} & Number & 14.8 & 18.1 & 34.7 & 32.3 & 37.4 & 26.7 & 24.3 & 11.6 \\
\hline & GDP & 43.6 & 21.3 & 21.8 & 13.3 & 60.1 & 20.0 & 12.8 & 7.2 \\
\hline & Population & 29.5 & 22.4 & 27.2 & 20.9 & 51.6 & 24.2 & 16.3 & 8.0 \\
\hline \multirow{3}{*}{$\begin{array}{l}\text { Less than one } \\
\text { hour }\end{array}$} & Number & 24.0 & 19.0 & 32.9 & 24.0 & 34.4 & 21.1 & 20.5 & 24.0 \\
\hline & GDP & 54.3 & 16.6 & 19.5 & 9.6 & 72.2 & 16.4 & 9.1 & 2.3 \\
\hline & Population & 39.4 & 19.9 & 25.4 & 15.3 & 62.8 & 20.6 & 12.9 & 3.7 \\
\hline \multirow{3}{*}{$\begin{array}{l}\text { One to two } \\
\text { hours }\end{array}$} & Number & 56.1 & 2.4 & 34.1 & 7.4 & 81.0 & 2.4 & 15.1 & 1.5 \\
\hline & GDP & 80.6 & 1.4 & 16.5 & 1.5 & 94.9 & 1.4 & 3.4 & 0.3 \\
\hline & Population & 72.1 & 2.2 & 22.9 & 2.8 & 91.7 & 2.1 & 5.6 & 0.6 \\
\hline
\end{tabular}

Note: The data are calculated based on the prefecture-level administrative units and are all given as percentage values.

\subsection{Major competitive markets}

Cities with a population of more than one million, especially megacities and very large cities, are the major competitive market for air transport and HSR. The coverage rates of different kinds of cities by the present HSR network are 100\% (megacities), 93.75\% (very large cities), 44.44\% (large cities), 30.51\% (medium-sized cities), and 9.89\% (small cities) (Table 4), which is much lower than the present coverage by airports (except for megacities and very large cities). Specifically, all three megacities (Beijing, Shanghai, Chongqing) and $87.5 \%$ of the very large cities have both airports and HSR stations in their administrative areas. Two very large cities have just an airport or a HSR station, namely, Shanwei in Guangdong Province and Xi' an in Shaanxi Province. Shanwei has only an airport; Xi'an has a HSR station and the nearest airport is located in Xianyang. Both air transport and HSR are convenient for people traveling in these cities, which leads them to be the major competitive market 
for air transport and HSR. The large, medium-sized, and small cities with airports accounted for $48.15,41.5$, and $52.75 \%$ of the total in 2012 , which is 1.08 times, 1.36 times, and 5.33 times that of the total for the HSR stations. Air transport covered more small and medium-sized cities than the HSR network. Only 5.08\% of the medium-sized cities and 3.3\% of the small cities had both HSR stations and airports in their administrative areas, so the competition between HSR and air transport is not well-defined. With the development of the planned HSR and air transport, the number of cities connected by the HSR network and air transport will increase to 216 and 206, which will lead to increasing competition between HSR and air transport. Specifically, people in all the megacities, $93.75 \%$ of the very large cities, $49.07 \%$ of the large cities, $29.66 \%$ of the medium-sized cities, and $23.08 \%$ of the small cities will in the future have choices for traveling by both HSR and air transport and these cities will become the major competitive market between HSR and air transport.

Table 4 Coverage of HSR stations and airports in the administrative areas of cities by population size, present and future

\begin{tabular}{clccccc}
\hline \multirow{2}{*}{ Time } & Administrative coverage & Megacity & Very large city & Large city & Medium-sized city & Small city \\
& & No. $(\%)$ & No. $(\%)$ & No. $(\%)$ & No. $(\%)$ & No. $(\%)$ \\
\hline \multirow{3}{*}{ Present } & $3(100)$ & $15(93.75 \%)$ & $48(44.44)$ & $36(30.51)$ & $9(9.89)$ \\
& HSR station only & $3(100)$ & $15(93.75 \%)$ & $52(48.15)$ & $49(41.5)$ & $48(52.75)$ \\
& Airport only & $3(100)$ & $14(87.5 \%)$ & $24(22.22)$ & $6(5.08)$ & $3(3.3)$ \\
& Both & $0(0)$ & $0(0)$ & $32(29.63)$ & $39(33.05)$ & $38(41.3)$ \\
\hline \multirow{3}{*}{ Planned } & Neither & $3(100)$ & $16(100)$ & $83(76.85)$ & $76(64.41)$ & $38(41.76)$ \\
& HSR station only & $3(100)$ & $15(93.75)$ & $64(59.26)$ & $64(54.24)$ & $60(65.93)$ \\
& Airport only & $3(100)$ & $15(93.75)$ & $53(49.07)$ & $35(29.66)$ & $21(23.08)$ \\
& Both & $0(0)$ & $0(0)$ & $14(12.96)$ & $13(11.02)$ & $15(16.3)$ \\
\hline
\end{tabular}

Most cities accessible to both HSR stations and airports within two hours have a population of over one million and these are the major competitive market of HSR and air transport (Table 5). Specifically, the megacities had the highest coverage rate (100\%) in the two hour service hinterland of HSR stations, which is much higher than that of the very large cities (93.75\%), 1.77 times that of large cities (56.48\%), 2.18 times that of medium-sized cities $(45.76 \%)$, and 8.36 times that of small cities $(11.96 \%)$. The coverage rates in the one hour service hinterland of airports showed the same trend as for HSR by size of a city, decreasing from megacities to small cities; $95.37 \%$ of large cities could reach the nearest airport within two hours by road transport, except for Shangqiu in Henan Province, Bijie in Guizhou Province, Ankang in Shanxi Province, Wuwei in Gansu Province, and Guigang in Guangxi Province. The coverage rate for airports within two hours was $52.17 \%$ for small cities, 4.36 times that for the HSR stations, and $54.24 \%$ for medium-sized cities, 1.89 times that for the HSR stations. In other words, air transport had a higher coverage rate over HSR in small and medium-sized cities. With regard to the GDP indicator, the coverage rate of air transport in small and medium-sized cities was much higher than for HSR. After the opening of planned airports and the HSR network, the overlapping market of HSR and air transport will greatly expand, especially in small and medium-sized cities. Specifically, the coverage rates of the two hour service hinterlands of airports and HSR were $48 \%$ and $66.3 \%$ for small cities and $54.24 \%$ and $68.64 \%$ for medium-sized cities, respectively. Megacities and very large cities are still the major competitive market of HSR and airports. All the megacities and very large 
cities are simultaneously located in the two hour service hinterlands of airports and HSR. Spatially, the small and medium-sized cities, which are accessible to the present HSR stations and airports within two hours, are located along the trunk HSR lines or around the megacities and very large cities (such as Beijing, Shenyang, Shijiazhuang, and Shanghai). Those cities accessible to the planned HSR stations and airports within two hours will expand to the western region, especially Yunnan Province and along the Lanzhou-Urumqi corridor.

Table 5 Cities accessible to HSR stations and airports within two hours by road transport, present and future

\begin{tabular}{cccccc}
\hline Classification & Indicator & $\begin{array}{c}\text { Present HSR } \\
\text { stations }\end{array}$ & Present airports & $\begin{array}{c}\text { Planned HSR } \\
\text { stations }\end{array}$ & Planned airports \\
& Number (\%) & $3(100)$ & $3(100)$ & $3(100)$ & $3(100)$ \\
Megacity & GDP (billion yuan) (\%) & $4545.9(100)$ & $4545.9(100)$ & $4545.9(100)$ & $4545.9(100)$ \\
& Number (\%) & $15(93.75)$ & $16(100)$ & $16(100)$ & $16(100)$ \\
Very large city & GDP (billion yuan) (\%) & $9322.2(98.65)$ & $9449.8(100)$ & $9449.8(100)$ & $9449.8(100)$ \\
& Number (\%) & $61(56.48)$ & $61(56.48)$ & $97(89.81)$ & $73(67.59)$ \\
Large city & GDP (billion yuan) (\%) & $15927.4(69.86)$ & $15957.8(70.00)$ & $21331.0(93.57)$ & $238.1(1.04)$ \\
Medium-sized & Number (\%) & $54(45.76)$ & $64(54.24)$ & $84(71.19)$ & $81(68.64)$ \\
city & GDP (billion yuan) (\%) & $6421.3(56.08)$ & $6472.9(56.53)$ & $8916.0(77.87)$ & $8084.4(70.60)$ \\
Small city & Number (\%) & $11(11.96)$ & $48(52.17)$ & $37(40.22)$ & $61(66.30)$ \\
& GDP (billion yuan) (\%) & $1130.3(24.87)$ & $2491.6(54.83)$ & $2504.3(55.11)$ & $3360.7(73.96)$ \\
\hline
\end{tabular}

Data are presented as number (\%).

\subsection{Distance to the city center}

Apart from the population scale, the distance from the city center to the nearest HSR stations or airports also has some influence on the choice to travel by air transport or HSR. On average, it is much more convenient for people to travel from the city center to the nearest HSR stations than to an airport. In 2012, the average distance of HSR stations from the nearest city center was around $23.2 \mathrm{~km}$, which was much lower than that of airports $(32.59 \mathrm{~km})$. Most HSR stations were located $<15 \mathrm{~km}$ from the city center, while airports were mainly located 10-30 km from the city center. Overall, the number of HSR stations versus the distance to the city center conformed to the distance decay rule, with some minor fluctuations at distances of 20-25, 35-40, 55-60, and 85-90 km (Figure 6). The number of airports versus distance to the city center conformed to the distance decay rule when the distance was

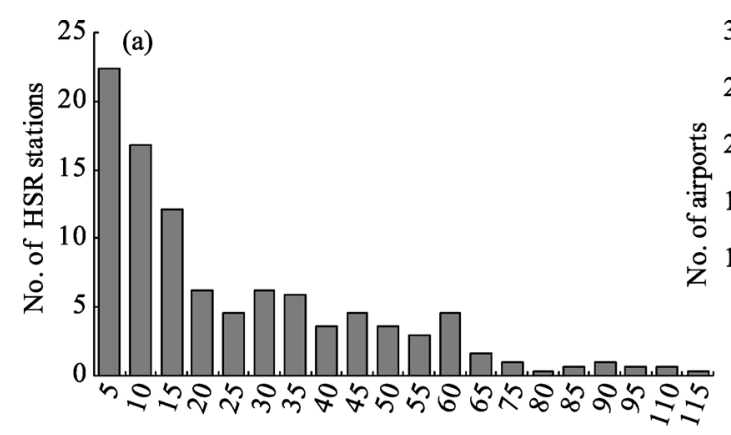

Distance to the nearest city center

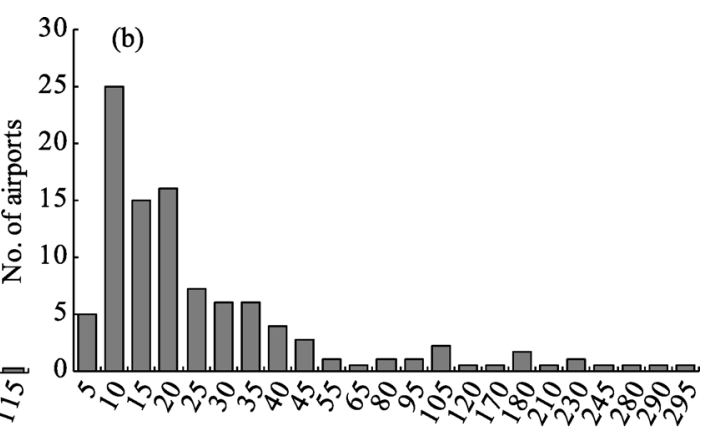

Distance to the nearest city center

Figure 6 Number of the HSR stations and airports versus the shortest distance to the city center 
$>5 \mathrm{~km}$, with some fluctuations at distances of 15-20, 95-105, 170-180, and 210-230 km. In other words, the HSR stations located within $10 \mathrm{~km}$ of the city center had advantages over airports for intra-city traveling time, whereas those located $10-30 \mathrm{~km}$ from the city center had a similar travel time by road transport to that of the airports. Therefore the latter cities were more competitive than the former for the two transport modes. No HSR station was located $>115 \mathrm{~km}$ from the city center, whereas 11 airports were located $>115 \mathrm{~km}$ from the city center. In these cities, people are more likely to travel by HSR for short and medium distances if other conditions are comparable.

\section{Conclusions and discussion}

The rapid development of HSR and air transport has been changing the market structure of transport in China since the beginning of the 21 st century. Both modes of transport are high speed, high cost, and comfortable, which means that there will inevitably be competition between them. Passenger demand is rapidly developing and shows variety. According to the technical and economic characteristics of HSR and air transport, HSR will not simply be the substitution of air transport. The development of HSR largely affects the passenger flow of air transport over a short period of time, but over a long period the impact of HSR on the passenger flow of air transport is unclear. Therefore recognition of the service hinterland and the selection of a suitable passenger market, enhanced cooperation and a reduction in the competition between HSR and air transport are important in promoting the sustainable development of the transport infrastructure in China. By comparing the service hinterland of HSR and air transport, the following conclusions can be drawn.

First, the difference in technical and economic characteristics of HSR and air transport will determine their advantage market. It is much more difficult to build HSR lines than airports in western China as a result of the harsh natural terrain and climate, which makes the western region an advantage market for air transport. HSR is suitable for travel over short or medium distances, whereas air transport is more advantageous over long distances. Air transport concerns the flow of passengers between their origin and destination, whereas the flow of passenger on an HSR line is influenced by all the cities along the line. Therefore most of the HSR lines are located in densely populated and developed regions. The service hinterland of the present HSR network is mainly concentrated in the eastern and central regions of China, while that of the airport network is much more dispersed and could be found in the peripheral areas. The peripheral areas of China (such as northwest China) are usually large in area and sparsely populated with harsh natural conditions; it is difficult to attract sufficient passengers for HSR lines and therefore the development of air transport is more suited to these areas. Therefore the Civil Aviation Administration of China should plan airports in these areas and develop sub-lines there. The HSR network should be constructed in the densely populated and economically developed regions. In the urban agglomeration regions, it is much more efficient to construct an HSR network to connect with airports, which not only expands the hinterland of airports, but also encourages the sharing of multi-airport systems and cooperation between HSR and air transport.

Second, urban agglomerations and national economic corridors are the areas that concentrate dense passenger flows and are also the competitive market of HSR and air transport. The service hinterland of HSR in 2012 was mainly concentrated in the regions located at the 
east of the Harbin-Beijing-Guangzhou line, especially the Bohai Rim region, the Pearl River Delta region, and the Yangtze River Delta area, with high population densities and well-developed economies; these areas are also the service hinterland of airports. Therefore these regions are the main competitive market for both HSR and air transport.

Air transport with a travel distance $<600 \mathrm{~km}$ only has a small percentage of passengers $(13.7 \%)$ in the whole air market (Zhang and $\mathrm{Hu}, 2010)$ and therefore HSR has very little impact on air transport in the short-haul travel market. The construction of HSR lines has a larger impact on air transport for medium-haul travel, such as the Beijing-Shanghai PDL, the Beijing-Harbin PDL, and the Wuhan-Guangzhou PDL. In regions where HSR and air transport have a large overlap in the service market, or for the city pairs where the travel time by air transport is much closer to that of HSR, the air transport sector should readjust their timetables, optimize airlines, increase the punctuality of flights, and enhance the connectivity of air transport and other transport modes to increase their market share. In terms of short-haul travel, the airlines may have to reduce the frequency of flights or even cancel them altogether.

Third, the construction of the HSR lines in the western region of China is debatable. Based on the planning of HSR and air transport, the overlapping of the service hinterland will increase and expand spatially from the eastern region to the western region. The number of cities with both HSR stations and airports will increase from 50 in 2012 to 131 when the planned HSR network and airports open. Inner Mongolia, Xinjiang, Ningxia, Gansu, Yunnan, and Guizhou provinces will become overlapping markets for HSR and air transport. The number of airports located in the one or two hour service hinterlands of HSR will increase more obviously. As the HSR network expands to the western region of China, the transport distance will exceed the economic distances for HSR. This will lead to an increase in the construction cost and a shortage of passenger flows, resulting in unexpected competition with air transport. As there are so many problems for the development of HSR in the western region of China today, some HSR projects, especially the planned projects with speeds $>300 \mathrm{~km} / \mathrm{h}$, should be canceled or slowed down during the construction stage.

Finally, the competition between air transport and HSR is not only reflected by the overlapping service market, but also by the fares, frequency, travel distance, departure time, and distance from airports/HSR stations to the city center. If all the other factors remain constant, the grade and scale of airports and the HSR stations also influence the range of the service market. This work aimed to analyze the overlapping markets of HSR and air transport from a geographical perspective and to study the competition between HSR and air transport. Although there are some limitations - for example, travel tickets were not considered - this work makes a contribution to the theory and practice of competition between HSR and air transport. In future studies, many more factors should be considered to analyze the relationship between HSR and air transport to give a more comprehensive perspective.

\section{References}

Adler N, Pels E, Nash C, 2010. High-speed rail and air transport competition: Game engineering as a tool for cost-benefit analysis. Transportation Research Part B: Methodological, 44(7): 812-833.

Bel R, 1997. Changes in travel time across modes and its impact on the demand for inter-urban rail travel. Transportation Research Part E: Logistics and Transportation Review, 33(1): 43-52.

Capon P, Longo G, Santorini F, 2003. Rail vs. air transport for medium range trips. In: 7th International Confer- 
ence on Traffic Science, Nova Gorica, 6-8 November 2003, 12(6-8): 1-11.

Chen J, 2010. International practice of civil aviation competing against high-speed trains. China Civil Aviation, 117(9): 20-21.

Civil Aviation Administration of China (CAAC), 2011. China Civil Aviation Development Twelfth Five-Year Plan. http://www.caac.gov.cn/I1/I2/201105/t20110509_39615.html (accessed 05.09.2011). (in Chinese)

Curtis C, Scheurer J, 2010. Planning for sustainable accessibility: Developing tools to aid discussion and decision-making. Progress in Planning, 74(2), 53-106.

Ding D, 2009. Impacts of high-speed rail on civil aviation. Air Transport \& Business, 16(24): 16-18. (in Chinese)

Directorate General of Transport, European Commission (DGT, EC), 1998. Transport Research: COST 318. Interaction between High Speed Rail and Air Passenger Transport, Final Report of the Action. Luxemburg: Office for the Official Publications of the European Communities.

Dobruszkes F, 2011. High-speed rail and air transport competition in western Europe: A supply-oriented perspective. Transport Policy, 18: 870-879.

González-Savignat M, 2004. Competition in air transport: The case of the high speed train. Journal of Transport Economics and Policy, 38(1): 77-108.

Guo C, 2010. Research on the game theoretical model of passenger traffic sharing between high-speed rail and civil aviation [D]. Beijing: Beijing Jiaotong University. (in Chinese)

Hansen W G, 1959. How accessibility shapes land-use. Journal of the American Institute of Planners, 25(2): 73-76.

Huang J, 2010. Development of high-speed rail and its impacts on air transportation. Productivity Research, 9: $144-146$.

Jiao J, Wang J, Jin F et al., 2014. Impacts on accessibility of China's present and future HSR network. Journal of Transport Geography, 40: 123-132.

Liu Y, Li Y, Wen L, 2007. The impact of the sixth speed increase of railway and recommendations to civil aviation industry. China Civil Aviation, 33(10): 30-32. (in Chinese)

Mao J, 2010. Air vs rail competition towards the Beijing-Shanghai high-speed rail project in China. Journal of Air Transport Studies, 1(2): 42-58.

Meng D, Lu Y, 2012. Impact of high-speed rail on accessibility and economic linkage of cities along the railway in Henan province, China. Scientia Geographica Sinica, 31(5): 537-543. (in Chinese)

Ministry of Civil Affairs of the People's Republic of China, 2013. The Administrative Divisions of China. Beijing: SinoMaps Press.

MOR, China's Ministry of Railway, 2008. Mid-to-Long Term Railway Network. Plan. Report http://www.chinamor.gov.cn/tljs/tlgh/201012/t20101228_731.html (accessed 21.11.10). (in Chinese)

National Bureau of Statistics of China (NBSC), 2012a. China City Statistical Yearbook. Beijing: China Statistics Press.

National Bureau of Statistics of China (NBSC), 2012b. China Population and Employment Statistical Yearbook. Beijing: China Statistics Press.

National Bureau of Statistics of China (NBSC), 2012c. China's Regional Economic Statistical Yearbook. Beijing: China Statistics Press.

National Development and Reform Commission, 2013. Yearbook of China Transportation \& Communication. Beijing: China Transportation Yearbook Press.

Park Y, Ha H, 2006. Analysis of the impact of high-speed railroad service on air transport demand. Transportation Research Part E: Logistics and Transportation Review, 42(2): 95-104.

Peng Z, Hu H, 2009. Effects of high-speed train on air transportation. Comprehensive Transportation, 31(7): 70-75.

Román C, Espino R, Martin J C, 2007. Competition of high-speed train with air transport: The case of Madrid-Barcelona. Journal of Air Transport Management, 13(5): 277-284.

Román C, Espino R, Martin J, 2010. Analyzing competition between the high speed train and alternative modes: the case of the Madrid-Zaragoza-Barcelona Corridor. Journal of Choice Modelling, 3(1): 84-108.

Wang F, 2010. The analysis about the impact of the high-speed rail on civil aviation's operation [D]. Beijing: Beijing Jiaotong University. (in Chinese)

Wang J, Ding J, 2011. High-speed rail and its impacts on the urban spatial structure of China. Urban Planning International, 26(6): 47-52. (in Chinese)

Wang J, Lin C, 2011. High-speed rail and its impacts on the urban spatial dynamics in China: The background and analytical framework. Urban Planning International, 36(1): 16-23. (in Chinese)

Wang J, Jin F, Sun W et al., 2006. Research on spatial distribution and service level of Chinese airport system. Acta Geographica Sinica, 61(8): 829-838. (in Chinese)

Zhang L, Hu H, 2010. Effects of high-speed train on civil air passengers. Comprehensive Transportation, 3 : 65-70. 